\title{
RESPONSABILIDAD PROFESIONAL: FALTA DE TRATAMIENTO UNIVOCO
}

\author{
José Manuel Fernández Hierro
}

\begin{abstract}
Sumario: 1. Diversidad de actuaciones profesionales. 2. La medida de la culpa. 2.1. Actividades en la construcción. 2.2. Responsabilidad médica. 2.3. Profesiones jurídicas. 2.3.1. Abogados y procuradores. 2.3.2. Notarios y registradores. 2.3.3. Jueces. 3. La prueba de la culpa. 3.1. Construcción. 3.2. Médicos. 3.3. Profesiones jurídicas. 3.3.1. Abogados y procuradores. 3.3.2. Notarios y registradores. 3.3.3. Jueces y magistrados. 4. Prescripción. 4.1. Construcción. 4.2. Médicos. 4.3. Profesiones jurídicas. 4.3.1. Abogados y procuradores. 4.3.2. Notarios y registradores. 4.3.3. Jueces y magistrados. 5. Conclusión.
\end{abstract}

\section{Diversidad de actuaciones profesionales}

Si la responsabilidad civil es una de las materias jurídicas que más auge e incremento han tenido en el presente siglo, uno de los campos en que particularmente se ha desarrollado es en el de la responsabilidad profesional, en el que los litigios han aumentado espectacularmente ${ }^{1}$.

1 Véase sobre este particular: HuET, Responsabilité contractuelle et responsabilité délictuelle. Essai de délimitation entre les deux ordres de responsabilité, París, 1978; JoRDANO FRAGA, La responsabilidad contractual, Madrid 1991; LEGA, Carlos, La libera professioni intelectuali nell leggi e nella giutrsprudenza, Milán 1974; LEROY, M. Contribution à l'étude des obligations du professionnel (les devoirs de répondre des risques créés par l'activité et le devoir de maîtrise professionnelle), Toulouse, 1995; Martínez CAlCerRada, La responsabilidad civil profesional, Madrid 1996; Sotomayor GIPPINI, Introducción a la responsabilidad civil profesional en «Conferencias sobre el Seguro de Responsabilidad Civil», Bilbao 1979; TRIGo REPRESAS, Responsabilidad civil de los profesionales, Buenos Aires 1978; e YZQUIERDo TOLSADA, La responsabilidad civil del profesional liberal, Madrid 1989. 
Pero conviene advertir que no a todos los profesionales se les ha exigido con la misma intensidad o con el mismo rigor la responsabildad civil: así, en nuestro ordenamiento jurídico prácticamente no existen casos de exigencia de responsabilidad civil a periodistas ${ }^{2}$ (salvo los procedimientos de rectificación o los entablados en virtud de la Ley de Protección del Honor y de la Intimidad) ni a los políticos (si pueden considerarse profesionales); pero no sólo a tales categorías, sino a otras muchas, como pudieran ser los meteorólogos ${ }^{3}$, informáticos, administradores de inmuebles, ingenieros agrícolas o de montes, técnicos en electricidad, etc.

En realidad casi todas de las reclamaciones por responsabilidad civil contra profesionales en nuestro ordenamiento jurídico (dejando aparte el campo más numeroso de las reclamaciones que la conducción de vehículos de toda clase origina por las correspondientes especialidades de este sector, e incluso la propia condición de los conductores como profesionales) han tenido su origen en cuatro actividades:

a) Aquellas relacionadas con la construcción y tráfico inmobiliario.

b) Las que hacen relación con la medicina, y

c) Las profesiones jurídicas.

Evidentemente que el campo de la responsabilidad profesional no se agota ahí pero, hoy por hoy, la inmensa mayoría de las demandas de responsabilidad civil se han circunscrito a las actuaciones que tengan referencia con la actividad constructora, médica o jurídica.

Con tales premisas, se plantea el interrogante, independientemente de las que pueda entrar sobre la propia aplicación ${ }^{4}$, de si cabe el tratamiento unificado de la responsabilidad civil profesional.

Para contestar podemos examinar el tratamiento que tres puntos concretos, pero importantes, reciben según la clase de profesional de que se trata. Tales extremos son, en primer lugar, la medida de la culpa, en segundo lugar la prueba de la culpa y en tercer lugar el periodo de prescripción o de garantía.

2 Otra cosa es el derecho francés, en que las condenas a periodistas son relativamente numerosas: así, Civ. 2. 21 de enero de 1987, D. 87, información rápida. 25, París 14 de mayo de 1988, D. 88, información rápida 104, París 26 de marzo de 1987, D. 87, información rápida 104, Civ. 2. 5 de mayo de 1993.

3 Ejemplo de lo contrario en derecho americano es el tratado por YzQUIERdo TolsadA, obra citada, p. 5.

4 Véase De Angel YÁGüEz, Algunas previsiones sobre el futuro de la responsabilidad civil, con especial atención a la reparación del daño, Madrid 1995, pp. 229 y ss. 


\section{La medida de la culpa}

En un supuesto de responsabilidad civil es esencial el parámetro que se pueda tener para medir, salvo si se adopta un criterio de responsabilidad objetiva que la eluda superándola.

Es sabido que el artículo 1.104 del Código Civil establece como pauta de comportamiento el criterio del buen padre de familia, criterio que, aún cuando es ridiculizado a veces por la doctrina, sigue vigente en la actualidad, en diversos ordenamientos jurídicos que han recogido la antigua tradición existente al respecto ${ }^{5}$.

Ahora bien, cuando se ha tratado de actividades profesionales el Tribunal Supremo ha precisado que el modelo de comparación era el del buen profesional.

El concepto de diligencia profesional viene en la jurisprudencia unido a un mayor nivel de exigencia con el pensamiento implícito de que el profesional debe ser más cuidadoso en las actividades de su especialidad que el hombre ordinario:

«Por otra parte hay que avanzar también, en orden a la diligencia debida, que la normal previsión exigible al Arquitecto-Director de la obra, no cabe confundirse con la simple diligencia de un hombre cuidadoso, sino que es aquella obligada por la especialidad de sus conocimientos y la garantía técnica y profesional que implica su intervención en la obra, siendo esta especial diligencia la que debe serle exigida» ${ }^{6}$.

Posteriormente los Tribunales aplicaron a la culpa profesional el criterio de la lex artis y el de la lex artis ad hoc, que según el Tribunal Supremo - concretado en un supuesto de responsabilidad en la medicina- es:

«Aquel criterio valorativo de la corrección del concreto acto médico ejecutado por el profesional de la medicina — ciencia o arte médicaque tienen en cuenta las especialidades características de su autor, de la profesión, de la complejidad y trascendencia vital del paciente y, en su caso, de la influencia en otros factores endógenos — estado e intervención del enfermo, de sus familiares, o de la misma organización sanitaria-,

5 Es de notar que aunque el artículo 1.104 es aplicable exclusivamente a la culpa contractual, según la jurisprudencia puede extenderse a la extracontractual: así sentencia 20 de marzo de 1990, Ar. 1.710.

6 S. 29 de marzo de 1966, Ar. 1.670. 
para calificar dicho acto de conforme o no con la técnica normal requerida (derivando de ello tanto el acervo de exigencias o requisitos de legitimación o actuación lícita, de la correspondiente eficacia de los servicios prestados y, en particular, de la posible responsabilidad de su autor/médico por el resultado de su intervención o acto médico ejecutado)» ${ }^{7}$.

Como he señalado en otro lugar ${ }^{8}$, la lex artis, que parece un parámetro de conducta más que una concreción de los deberes, tiene el peligro de poderse considerar como una norma en blanco; y en cuanto a la lex artis ad hoc, concreción de lo anterior, que remite a las normas médicas, cabe sea entendida como una remisión a las normas profesionales, de forma que hasta se podría opinar que es el mismo acto el que genera, por una especie de mecanismo de autorregulación, su propia ley con la que habría de juzgarlo.

Ahora bien, ¿tales criterios son siempre aplicables a la responsabilidad profesional?

Vamos a distinguir los grupos de actividades antes señalados.

\subsection{Actividades en la construcción}

Las responsabilidades en la construcción se derivan en gran manera, en nuestro ordenamiento jurídico, de un precepto específico del artículo 1.591 del Código Civil.

La dicción del artículo 1.591 del Código Civil supone una presunción de culpa para el edificio que se arruinara dentro del plazo de garantía que

7 S. de 11 de marzo de 1991, artículo 2.209. Y sigue diciendo la misma sentencia que las notas características de la lex artis ad hoc son:

«1) como tal "lex" implica una regla de medición de una conducta, a tenor de unos baremos, que valoran la citada conducta; 2) Objetivo: valorar la corrección o no del resultado de dicha conducta, o sea, que esa actuación médica sea adecuada o se corresponda con la generalidad de conductas profesionales ante casos análogos; 3) Técnica: los principios o normas de la profesión médica en cuanto ciencia se proyectan al exterior a través de una técnica y según el arte personal de su autor o profesionalidad: el autor o afectado por la "lex" es un profesional de la medicina; 4) El objeto sobre que recae: especie de acto (clase de intervención, medios asistenciales, estado del enfermo, gravedad o no, dificultad de ejecución); 5) Concreción de cada acto médico o presupuestos "ad hoc": tal vez sea éste el aporte que individualiza a dicha "lex artis": así como en toda profesión rige una "lex artis' que condiciona la corrección de su ejercicio, en la médica esa "lex", aunque tenga un sentido general, responde a las peculiaridades de cada acto, en donde influirán en un sentido u otro los factores antes vistos; y finalmente en cuanto a los requisitos de la responsabilidad del médico y características de su profesión».

8 Sistema de responsabilidad médica, Granada 1997, pp. 202 y ss. 4 
en él se contiene, y así lo ha entendido tanto la doctrina ${ }^{9}$ como la jurisprudencia ${ }^{10}$.

La responsabilidad civil en la construcción no se agota con las acciones del artículo 1.591 del Código Civil, pero también por el ejercicio de las acciones de los artículos 1.907 al 1.909 del Código Civil se admite la presunción de culpa ${ }^{11}$.

La presunción de culpa en la construcción también se ha utilizado en otros ordenamientos jurídicos, como el francés, desarrollando el artículo 1.792 del Código Napoleón ${ }^{12}$, e incluso en sistemas jurídicos alejados del nuestro, como el americano, aplicando el principio de res ipsa loquitur.

Tales aplicaciones han hecho que sea innecesario en la mayoría de los supuestos de responsabilidad de la construcción llegar a comparar la actuación profesional con el parámetro de la lex artis: si se presume que todo vicio grave constructivo se ha producido por culpa de los técnicos o constructores no es necesario llegar a aplicar una regla comparativa para medir la conducta, diligente o no, de estos: simplemente habrá que demostrar si la ruina o vicio grave se ha producido dentro del periodo de garantía y, en todo caso, será el arquitecto o aparejador el que deberá demostrar que no le son imputables los defectos existentes. Tal caracterización, próxima a la responsabilidad objetiva, hace que sólo en casos aislados se acuda a la regla de la lex artis cuando se trata de responsabilidad en la construcción.

\subsection{Responsabilidad médica}

En el campo de la responsabilidad médica es donde con más reiteración y paridad se ha aludido a la lex artis y a la lex artis ad hoc como parámetros comparativos.

9 Cadarso Palau, La responsabilidad decenal de arquitectos y constructores, Madrid 1976, pp. 171 y ss.; Fernández Costales, El contrato de arquitecto en la edificación, Madrid 1977, p. 375. FERNÁNDEZ HIERRO, La responsabilidad civil por vicios de construcción, Bilbao, 1976, pp. 93 y ss. GARCía CANTERO, La responsabilidad por ruina de los edificios en el artículo 1.591 del Código Civil en ADC 1.963, p. 1.105, y Herrera Catena, Las responsabilidades en la construcción, vol. II, Granada 1977, pp. 124 y ss.

10 Ss. 31 de enero 1985, Ar. 223, 29 de noviembre de 1985, y 22 de abril de 1988, Ar. 327, entre otras.

11 S. 26 de noviembre de 1990, Ar. 9.407.

12 Civ. 3. e, 14 de diciembre 83, D. 1984, inf. 159; Req.16 de julio 89, D. 1990. 1.448; Civ. 3. 3 de junio 1992. 
Notemos, hablando de responsabilidad médica, que infracción de la lex artis no significa error de diagnóstico, ya que el error de diagnóstico por sí no es constitutivo de culpa ${ }^{13}$, habiéndose mantenido que el error profesional en sí mismo, si no hay otros ingredientes, no genera culpa ${ }^{14}$ : así lo ha entendido la jurisprudencia francesa ${ }^{15}$. En España existen una larga serie de sentencias que señalan que el error de diagnóstico no es punible, salvo cuando es grosero o cuando el error ha sido motivado por no tomar los estudios y medidas necesarias y previas a la emisión del diagnóstico ${ }^{16}$.

\subsection{Profesiones jurídicas}

\section{3.1. Abogados y procuradores}

Cuando se trata de servicios del abogado, por una parte se ha aludido a que la negligencia exigible al abogado es mayor que la de un simple padre de familia ${ }^{17}$, mientras que en otros fallos se ha indicado concretamente la aplicación de la lex $\operatorname{artis}^{18}$.

En el supuesto de un graduado social, habiéndose promovido la demanda por mal asesoramiento del profesional, el Tribunal Supremo en sentencia de 5 de julio de $1991^{19}$ entiende que no cabe aplicar la teoría del riesgo a dicho profesional, y también la sentencia de la A.P. de Pontevedra de 23 de marzo de $1994^{20}$ mantiene que hace falta demostrar la culpa o negligencia del procurador.

Según la sentencia del Tribunal Supremo de 4 de febrero de $1992^{21}$ :

13 Fernández Hierro, Responsabilidad Civil médico-sanitaria, Pamplona 1983, pp. 88 y ss.

14 YzQuierdo TolsadA, obra citada, p. 296 y ss.

15 Véase GonZález Morán, La responsabilidad civil del médico, Barcelona 1990, pp. 99 y ss.

16 Ss. 29 de marzo de 1988, Ar. 2.124 y 10 de diciembre de 1996. Así la sentencia de 8 de octubre de 1963, Ar. 4.012 indica: «... lo que se incrimina y da origen a la responsabilidad criminal médica, no son errores de diagnóstico ni aun falta de extraordinaria pericia en el desarrollo de actividades quirúrgicas, al no ser exigibles en éste ni en ningún aspecto de la vida social la infalibilidad, sino que la culpa estriba en un comportamiento inadecuado a determinadas exigencias y medios».

17 S. A.P. de Valencia de 28 de septiembre de 1994, Ar. Civil 1.461 de 1994.

18 S. A.P. de León de 16 de diciembre de 1994, Ar. Civil 2.226 de 1994.

19 Ar. 5568.

20 Ar. Civil 544.

21819. 
«Cabe estimar correctamente invocados los preceptos del Estatuto de la Abogacía, pues aunque es reiteradísima la jurisprudencia de esta Sala según la cual no pueden servir de apoyo a la casación por el número $5 .^{\circ}$ del artículo 1.692 los preceptos reglamentarios, también es constante el criterio de admitirlos cuando, como en este caso, tienen el soporte legal del contrato de arrendamiento de servicios al cual se puede asimilar la actividad profesional, y el soporte del artículo 1.902 del Código Civil cuando la actuación profesional fuera de los límites contractuales produzca daños.

Ambos preceptos legales imponen al abogado actuar con diligencia, cuya exigencia debe ser mayor que la propia de un padre de familia dados los cánones profesionales recogidos en su Estatuto y que sirven de buena y estricta medida de su actuación».

\subsubsection{Notarios y registradores}

Determinadas profesiones jurídicas, como los registradores, tienen una normativa específica ${ }^{22}$, e igualmente la tienen los notarios, y lo mismo puede decirse de los agentes mediadores; en todos esos supuestos se trata de actividades realizadas por profesionales que no son funcionarios, pero que ejercen una función pública, aun cuando se trate de un ejercicio privado de tal función (hasta el punto de que su retribución está a cargo de quien requiera los servicios de estos profesionales, de acuerdo con lo previsto tanto en el reglamento notarial como en la Ley Hipotecaria): todo ello ha podido crear un confusionismo y una complicación en cuanto a la posible responsabilidad civil de los $\operatorname{mismos}^{23}$.

22 El artículo 296 de la Ley Hipotecaria señala las causas por las que responderán civilmente los registradores, y que son:

1. ${ }^{\circ}$ Por no asentar en el Diario, no inscribir o no anotar preventivamente en el término señalado en la Ley los títulos que se presenten al Registro.

$2 .^{\circ}$ Por error o inexactitud cometidos en inscripciones, cancelaciones preventivas o notas marginales.

$3 .^{\circ}$ Por no cancelar sin fundado motivo alguna inscripción o anotación, u omitir el ostento de alguna nota marginal, en el término correspondiente.

4. ${ }^{\circ}$ Por cancelar alguna inscripción, anotación preventiva o nota marginal, sin el título y los requisitos que exige esta Ley.

5. ${ }^{\circ}$ Por error u omisión en las certificaciones de inscripción o de libertad de los inmuebles o derechos reales, o por no expedir dichas certificaciones en el término señalado en esta Ley.

23 Sobre el problema de la responsabilidad subsidiaria o no del Estado como consecuencia de la actuación de tales profesionales dotados de función pública, véase la distinción que hace YZQUIERDO TOLSADA (obra citada, p. 117) entre funcionarios públicos y funcionario administrativo o funcionario del Estado. 
Existe una escasa jurisprudencia en cuanto a la responsabilidad de tales profesionales, la cual se derivará de la infracción de los deberes contenidos en la legislación específica que le sea aplicable ${ }^{24}$.

\subsubsection{Jueces}

Problema distinto es el de la responsabilidad en materia judicial: aquí nos encontramos con un profesional que es algo más que funcionario, porque es el ejercitador de una de las funciones esenciales del

24 Así por ejemplo la sentencia de la A.P. de Granada de 22 de julio de 1992, Ar. Civil 1.021 , tras sentar el principio teórico de la responsabilidad por riesgo, sigue precisando que no puede olvidarse de la necesidad de la culpa en un supuesto de responsabilidad extracontractual —así califica la responsabilidad de un Registrador de la Propiedad-, para continuar entendiendo que en el supuesto de autos no se deducía que la inscripción torticera de una finca comprometiera la responsabilidad del Registrador, precisando:

«Si bien es cierto (eso parece) que el evocado don Alvaro E. de P. (cuya identidad permanece en la sombra) llevó a cabo una acción punible perfecta, falsificación de una escritura de compraventa, creación "Ex novo" de una finca, que indujo a engaño a los señores hoy demandantes, tampoco es menos verdad que el acceso al Registro de la Propiedad de la finca imaginaria fue con rigor, pues no existían datos que permitiesen comprobar el fingimiento; en la inmatriculación de la finca rústica se observaron escrupulosamente por el señor demandado los presupuestos que se desprenden del artículo 205 de la Ley Hipotecaria, en relación con los artículos tercero de la misma, y el 298 del Reglamento para su aplicación, y téngase en cuenta que se acudió a este medio inmatriculador que terminamos de mostrar, al título público de adquisición, con los presupuestos y virtualidades que exigen los artículos de la Ley Hipotecaria y su Reglamento citados, y no al acta de notoriedad, a que se refiere el párrafo penúltimo del artículo 298 del Reglamento Hipotecario, en relación artículo 199 ap. b) de la Ley Hipotecaria, ni al Expediente de Dominio, artículos 199 ap. a), 201 y 202 de la Ley Hipotecaria y artículos 272 y siguientes de su Reglamento; por eso, y conectando esto que decimos, con el principio de "Legalidad", con la Calificación Registral que el mismo supone, vemos que aquí, el señor Registrador, cumplió con la obligación que le imponían los artículos 18, 99 y 100 de la Ley Hipotecaria y 98 y siguientes de su Reglamento; examinó el documento que se presentó ante el Registro (escritura pública de compraventa), y los antecedentes que contaban en el mismo, vio que el documento a calificar guardaba sus requisitos (téngase en cuenta que los Registradores calificarán los Documentos Notariales, limitándose a su contenido —el de la escritura-, a lo que resulte de los mismos, dejando a un lado especulaciones —que aquí era difícil que surgiesen-, que puedan impedir que el acto o contrato que reúna los requisitos necesarios para su inscripción ingrese en el Registro [R. 23-4-1881 y R. 5-8-1977]); por tanto, y como comprobó, insistimos, que en el Documento a calificar se daban las exigencias de forma que le eran exigibles, en este caso, las derivadas de su naturaleza notarial, la capacidad de los otorgantes no ofrecía duda, y la validez de los actos de creación (modificación) de una situación jurídico-real, contenida en el documento sometido a su calificación, tampoco, dio paso a la pretendida inscripción, una vez cumplidas las exigencias legales; con estas notas, que nos ponen de manifiesto que el Registrador opera conforme a los Títulos, a la verdad que manifiestan, y asimismo, de acuerdo con la realidad que fluye del Registro de la Propiedad, no podemos más que concluir, el examen conjunto de la prueba así lo dice, que el señor demandado no actuó negligentemente, y menos aún (como se apunta) arbitrariamente». 
Estado, razón por la que la posible responsabilidad del mismo ha tenido un tratamiento específico y diferenciado y además tal tratamiento ha sucedido en dicha forma en casi todos los países.

Por ese motivo, de la doble actuación del juez como profesional y como órgano del Estado, la exigencia de responsabilidad civil ha sido sumamente matizada en la mayoría de los ordenamientos jurídicos a lo largo de la historia, restringiendo la posibilidad a supuestos excepcionales como el derecho anglosajón o limitándose a los supuestos de dolo, fraude o confusión como en los ordenamientos franceses o italianos ${ }^{25}$.

El artículo 121 de la Constitución determina el derecho a ser indemnizado por los perjuicios que se causen como consecuencia del funcionamiento anormal de la Administración de justicia, y el 117-1 el de responsabilidad de jueces y magistrados.

El artículo 411 de la Ley Orgánica del Poder Judicial señala que los jueces y magistrados responderán civilmente de los daños y perjuicios que causaren cuando en el desempeño de sus funciones incurrieron en dolo o culpa ${ }^{26}$.

Ahora bien, la Ley de Enjuiciamiento Civil regula lo que se denomina recurso de responsabilidad civil de jueces y magistrados (art. 903 y siguientes), cuando infringen las leyes por negligencia o ignorancia inexcusables.

Como puede verse, la dicción de ambos textos es diferente, ya que mientras la Ley actual alude a dolo o culpa, la anterior señalaba el concepto de negligencia o ignorancia inexcusable, concepto que recoge también literalmente la Ley de Enjuiciamiento Civil en su artículo 903.

En otro lugar ${ }^{27}$ propugné que el artículo 903 de la Ley de Enjuiciamiento Civil citado podía ser anticonstitucional por rozar no sólo el principio de igualdad contenido en la Constitución, sino el precepto específico que señalaba la responsabilidad de jueces y magistrados sin limitarlo a las categorías que el referido texto procesal concretaba.

Pero la jurisprudencia no ha ido por ese derrotero, sino más bien ha exigido y rigurosamente los requisitos contenidos en la antigua Ley

25 Véase Fernández Hierro, Responsabilidad civil judicial, Pamplona 1987, pp. 15 y ss.

${ }^{26}$ El artículo 260 de la anterior Ley Orgánica del Poder Judicial de 18 de septiembre de 1970 señalaba: "La responsabilidad civil de los Jueces y magistrados estará limitada al resarcimiento de los daños y perjuicios estimables que causen a los particulares, Corporaciones o al Estado, cuando en el desempeño de sus funciones infrinjan las leyes por negligencia o ignorancia inexcusables».

27 Responsabilidad civil judicial, citada, p. 53. 
Orgánica del Poder Judicial y en la Ley de Enjuiciamiento Civil, repitiendo que la responsabilidad civil de jueces y magistrados se produce como consecuencia del ejercicio de sus funciones cuando hubieran incurrido en dolo o culpa y existieran por negligencia o ignorancia inexcusables $^{28}$.

Es más, el Tribunal Supremo se planteó si efectivamente había que atender solamente al artículo 411 de la Ley Orgánica del Poder Judicial y no al 903 de la Ley de Enjuiciamiento Civil, rechazando el argumento de que ya no eran exigibles el dolo, culpa o ignorancia inexcusables $^{29}$. Incluso los criterios para la exigencia de error judicial han sido sumamente rígidos, reservándose esta acción solamente para las decisiones injustificables desde el punto de vista del derecho ${ }^{30}$, que en definitiva, y como puede verse, los criterios para la exigencia de error judicial han sido notablemente más rígidos que los criterios para la exigencia de otras clases de responsabilidades.

28 Ss. 7 de febrero de 1994, Ar. 920 y 19 de febrero de 1994, Ar. 1.101.

29 S. 23 de septiembre de 1994, Ar. 6.936, dicha sentencia indica:

«La interpretación que la recurrente hace del artículo 411 de la Ley Orgánica del Poder Judicial ("Los Jueces y Magistrados responderán civilmente por los daños y perjuicios que causaren, cuando, en el desempeño de sus funciones, incurrieren en dolo o culpa"), no es asumible por esta Sala ya que la expresada redacción no supone una modificación de los criterios de limitación material de la responsabilidad de Jueces y Magistrados recogidos en el artículo 903 de la Ley Procesal Civil, pues tal redacción fue producto de una enmienda con finalidad de "corrección técnica" del Proyecto de la Ley Orgánica del Poder Judicial que se refería a "dolo, culpa grave o ignorancia inexcusable", y en tal sentido fue aceptada por la ponencia alegando que era una "simplificación en la redacción"; por tanto, en modo alguno se pretendió una modificación legislativa en el sentido aducido por la recurrente, lo que se corrobora por la subsistencia sin modificación alguna del citado artículo 903. La propia Ley Orgánica del Poder Judicial, al regular la responsabilidad patrimonial del Estado para el funcionamiento de la Administración de Justicia, limita esa responsabilidad, en su artículo 296, a "los daños que se produzcan por dolo o culpa grave de los Jueces y Magistrados", con lo que, de aceptarse la tesis recurrente, resultaría una evidente contradicción entre ambos preceptos, los artículos 411 y 296».

30 Ss. 4 de febrero de 1988, Ar. 589; 13 de abril de 1988, Ar. 3.143; 12 de enero de 1990, Ar. 33; 31 de noviembre de 1992, Ar. 7.247; 3 de marzo de 1993, Ar. 1.665; 14 de diciembre de 1993, Ar. 9.883; 7 de febrero de 1994, Ar. 920 («no es el desacierto lo que trata de corregir la declaración de error judicial, sino la desatención a datos de carácter indiscutible, generadora de una resolución esperpéntica, absurda, que rompe la armonía del orden jurídico»); 26 de diciembre de 1996, Ar. 9.397 (desatención, desidia o falta de interés jurídico); 22 de abril de 1996, Ar. 3.192 y 9 de diciembre de 1.996, Ar. 8.813 («habiendo de tratarse de un error craso, evidente e injustificado o, lo que es lo mismo, un error patente, indubitado e incontestable, que haya provocado conclusiones fácticas o jurídicas ilógicas o irracionales, generadoras de una resolución esperpéntica, o absurda, que rompa la armonía del orden jurídico»). También se ha señalado que la prisión provisional de un imputado declarado inocente no significa error judicial (S. 13 de mayo de 1999, Ar. 3.629). 


\section{La prueba de la culpa}

En la praxis jurídica, tan importante como la determinación de la clase de culpa necesaria para comprometer la responsabilidad de una persona, o más, es la demostración de la culpa o si el perjudicado puede probar una presunción de culpa o una inversión de carga de la prueba a su favor.

¿Son aplicables tales principios extendidos hoy en día de manera general dentro del ordenamiento jurídico a la responsabilidad profesional?

Vamos a distinguir los distintos campos profesionales:

\subsection{Construcción}

Dentro del capítulo de la construcción es donde más claramente se ha apreciado la presunción de culpa en contra del constructor, como antes se ha expuesto.

La razón puede radicar, por una parte, en la presunción de culpa contenida en el artículo 1.591 del Código Civil y, por otra parte, en la distinción entre obligaciones de medios y obligaciones de resultados, entendiendo que el contrato de obra es, por esencia, ejemplo típico de obligación de resultado $^{31}$. En cualquier caso la presunción de culpa en la construcción ex1.591 es clara $^{32}$, pero también es aplicable a los supuestos de otras acciones en la construcción, como las contenidas en los artículos 1.907 y concordantes del Código Civil como precisamente se ha expuesto.

\subsection{Médicos}

Como queda dicho, en la responsabilidad en materia médica no se admite la presunción de culpa de acuerdo con un criterio generalizado, lo cual va ligado con la conceptuación de la medicina como obligación de medios y no de resultados: el médico está obligado a proporcionar aquellos

31 Sobre la distinción entre obligaciones de medios y obligaciones de resultados puede verse CAVANILlas MúgICA y TAPIA FERnÁndeZ, La concurrencia en la responsabilidad contractual y extracontractual, tratamiento sustantivo y procesal, Madrid 1992; JORDANO FRAGA, Obligaciones de medios y de resultados (a propósito de alguna jurisprudencia reciente) en A.D.C. 1991, pp. 5. y ss.; LoBATo GómEZ, Contribución a la distinción entre las obligaciones de medios y las obligaciones de resultados, en A.D.C. 1.992, pp. 651 y ss.

32 FERNÁNDEZ HiERro. «La responsabilidad en la construcción según la Jurisprudencia civil» en Poder Judicial n. ${ }^{\circ}$ VII, p. 282. Ver también BARASSI, Instituciones de derecho civil, Barcelona 1966, tomo II, pp. 386, y ss., CunEo, Appalti publici e privati, Padua 1947, p. 633, Boubli, La responsabilité des architectes et entrepreneurs et autres locateurs d'ouvrages, París 1971, SoINNE, La responsabilité des architectes et entrepreneurs après la réception des travaux, París 1969. 
cuidados necesarios a fin de obtener la curación o el restablecimiento del paciente, pero no está obligado a obtener ésta salvo supuestos especiales: en definitiva, no se trata de un contrato de resultados.

Ciertamente la dificultad probatoria hace que en algunos casos ese principio deba ser matizado y suavizado y así lo he mantenido ${ }^{33}$. Si nos atenemos a la visión jurisprudencial, la inexistencia de presunción de culpa en contra del médico es mantenida casi universalmente, con algunas excepciones en la jurisprudencia civil reciente ${ }^{34}$, y con las excepciones también de los escasos supuestos en que la actividad médica puede considerarse de resultado (unos análisis simples, por ejemplo), y la responsabilidad de los órganos e instituciones de la sanidad pública hacia sus pacientes ${ }^{35}$.

\subsection{Profesiones jurídicas}

\subsubsection{Abogados y procuradores}

En cuanto a abogados y procuradores se ha estimado que la relación del abogado con el cliente es de un contrato de arrendamiento de servicios y no de obra ${ }^{36}$ y se ha insistido en que es la falta de celo y

33 Responsabilidad civil médico-hospitalaria, obra citada, pp. 127 y ss.

34 Así sentencia de 2 de diciembre de 1996.

35 Fernández Hierro, Sistema de..., obra citada, pp. 408 y ss.; RiverA Fernández, La responsabilidad médico-sanitaria y del personal sanitario al servicio de la administración pública, Valencia, 1997, pp. 67 y ss. VILlar RoJAs, La responsabilidad de las administraciones sanitarias: fundamento y límites, Barcelona 1996, p. 119. En cuanto a la posible aplicación de la Ley General para la Defensa de Consumidores y Usuarios a la Sanidad, véase DíAz-Regañón, El régimen de la prueba en la responsabilidad civil médica, Pamplona 1996, p. 369, Fernández Hierro, Sistema..., obra citada, pp. 120 y ss., Rivera FERnÁNDEZ, La responsabilidad médicosanitaria..., citada, pp. 83 y ss. Ver también PenNEAU, La responsabilité medicale, París 1992.

36 Así la sentencia de la Audiencia Provincial de Palencia de 15 de enero de 1997, Ar. Civil 1, señala:

«El contrato de arrendamiento de servicios difiere precisamente del contrato de arrendamiento de obra, en que mientras que en el primero es exigible al arrendador de los mismos la prestación de una serie de actividades, sin comprometerse un efectivo resultado, en el segundo se compromete un resultado concreto, siendo por tanto la obligación del arrendador de servicios, una obligación de medios, de concreta actividad, única que cabe exigir, pero que en el caso concreto del Abogado, profesional del derecho estriba en asuntos como el que nos ocupa en la realización de todas aquellas actividades tendentes a que su cliente, la otra parte contractual, obtenga una resolución sobre el fondo del asunto — artículo 359 LECiv—; salvo que el propio cliente haga ineficaz tal posibilidad, resolución sobre el fondo del asunto, que en este caso don Luis Angel no obtuvo debido a la falta de diligencia del demandado».

También la jurisprudencia francesa ha entendido que la responsabilidad del abogado es contractual hacia sus clientes aun cuando extracontractual hacia terceros (V. Civ. 1. ${ }^{\text {e }} 6$ de octubre de 1993, D. 96, Som. 108; Civ. 2. 15 de junio de 1994. D.94, Inf. 183). 
diligencia de los artículos 53 y 54 del Real Decreto 2.090/82 de 24 de julio, por el que se regula el Estatuto General de la Abogacía, los que originan responsabilidad civil ${ }^{37}$, pero señalando la necesidad de la demostración del incumplimiento por el profesional de sus obligaciones ${ }^{38}$ subrayando el carácter contractual de la obligación del abogado ${ }^{39}$.

La sentencia de la Audiencia Provincial de León de 16 de diciembre de $1994^{40}$ aplica la lex artis a la responsabilidad del abogado.

La doctrina también entiende que es el cliente el que debe demostrar la falta de diligencia del letrado ${ }^{41}$.

El Tribunal Supremo ha señalado que no es aplicable la inversión de carga de la prueba en un supuesto concreto de responsabilidad de $\operatorname{abogado}^{42}$.

\subsubsection{Notarios y registradores}

En cuanto a notarios, registradores y demás profesionales del derecho, entiendo que sería aplicable la doctrina sentada con carácter general por el Tribunal Supremo de que no es aplicable la presunción de culpa o la inversión de carga de la prueba tratándose de profesionales en general.

Lo mismo sucede en el ordenamiento francés, en el que la mayoría de la jurisprudencia ha entendido que no se puede aplicar la presunción de culpa contra los notarios ${ }^{43}$.

37 Sentencia citada de la A.P. de Palencia de 15 de enero de 1997. Ver también S. A.P. de Zaragoza de 16 de abril de 1993, Ar. Civil 418.

38 S. A.P. de Pontevedra de 23 de marzo de 1994, Ar. Civil 544.

39 S. A.T. de Oviedo de 28 de junio de 1984, R.G.D. p. 640 de 1985.

40 Ar. Civil 2.226.

41 Ver Avril, La Responsabilié de l'avocat, Paris, 1981, LaCruz, Elementos de Derecho Civil, tomo II, vol. 1. ${ }^{\circ}$, Barcelona 1985, pp. 236 y ss.; Egusquiza, María Angeles, La prestación de servicios del Abogado, en Aranzadi Civil, 1996, vol. I, pp. 185 y ss., MoNtoya Melgar y Cámara Botia, Abogados, profesión liberal y contrato de trabajo, Madrid 1990.

${ }^{42}$ La sentencia de 23 de diciembre de 1992, Ar. 10.715 señala en su fundamento jurídico sexto:

«En el undécimo y último motivo del recurso se invoca infracción "del artículo 1.214, en relación con el 1.902, ambos del Código Civil”. Se alega en este motivo que, según la doctrina jurisprudencial, incumbía a los demandados probar que actuaron con la debida diligencia, lo que ha sido desconocido por la Sala de instancia. Ha de rechazarse también este motivo en atención a que -independientemente de que de los autos resulta que la defensa se realizó normalmente y de que en los supuestos de responsabilidad por infracción de deberes profesionales no es de generalizada aplicación la inversión de la carga de la prueba (S. 24-5-1990)—》.

43 Civ. 30 de junio de 1987 D. 87, inf. 174. La excepción la constituyen aquellas operaciones que tienen un riesgo anormal, Civ. 1. 27 de septiembre de 1983, D. 84.369. 


\subsubsection{Jueces y magistrados}

Respecto a jueces y magistrados no solamente no opera la invasión de culpa ni la presunción de carga de la prueba, sino que la misma, como se ha visto, tiene que ser cualificada; si la responsabilidad del juez debe ser manifiesta difícilmente puede ser presumida.

Por ello, y como antes he señalado, el carácter restrictivo de las acciones de exigencia de responsabilidad civil contra jueces es general en el derecho comparado ${ }^{44}$.

\section{Prescripción}

Vamos a examinar los plazos de prescripción más comunes para ver también las coincidencias o diferencias entre los distintos profesionales.

\subsection{Construcción}

En materia del ejercicio de las acciones derivadas del artículo 1.591 del Código Civil, la mayoría de la doctrina ha entendido que hay que diferenciar plazo de garantía y término de prescripción, siendo el plazo de garantía de diez años y el de prescripción de quince años contados a partir de la producción del evento ruinógeno siempre que el mismo hubiera ocurrido dentro del periodo de garantía ${ }^{45}$.

44 Véase Fernández Hierro, Responsabilidad civil judicial, citada, pp. 15 y ss. También DE ANGEL YÁGÜEZ resalta el carácter restrictivo de la jurisprudencia del Tribunal Supremo sobre responsabilidad judicial, si bien aplicado a la fijación de daños, «Reciente jurisprudencia en materia de daños derivados de actuaciones judiciales civiles», en La Ley de 14 de febrero de 1986.

45 Del Arco y Pons, Derecho de la construcción, Madrid 1980, p. 362, FernándeZ Hierro, La responsabilidad civil..., obra citada, p. 148, FERnÁndez Costales, obra citada, pp. 144 y ss., Gómez DE LA EsCALERA, La responsabilidad civil de los promotores, constructores, y técnicos por los defectos de construcción (Estudio del artículo 1.591 del código Civil y su problemática actual) Barcelona 1990, p. 210 y ss., HerRera CATENA, obra citada, vol. II, p. 16, RUBIO SAN ROMÁN, La responsabilidad civil en la construcción, Madrid 1987, p. 198, y SÁNCHEZ CALERO, El contrato de obra, su cumplimiento, Madrid 1978, pp. 121 y ss.

En cambio la tesis del plazo único sin distinción entre periodo de garantía y plazo de prescripción es la dominante en la doctrina y la jurisprudencia francesas desde la decisión de las Cámaras reunidas de 2 de agosto de 1882 (D.P. 83.I.5) y la ha mantenido en nuestro derecho Travieses, «Contrato de arrendamiento», en Revista de Derecho Privado, 1991, pp. 34 y ss. 
La jurisprudencia ${ }^{46}$ también ha entendido de forma clara que es distinto plazo de garantía y plazo de prescripción y que puede reclamarse mientras no haya transcurrido el plazo de prescripción, que a su vez se inicia desde que se produzca el daño, siempre que éste se haya evidenciado dentro del término de garantía. Poniendo un ejemplo, si nos encontramos con unos vicios que se descubren $-\mathrm{y}$ se demuestra que en aquel momento se evidencian- a los 9 años de terminada la construcción del edificio, el plazo de prescripción se cuenta a partir de dicha fecha; con lo cual, en realidad, los perjudicados podrían presentar su demanda hasta 24 años después de terminado el inmueble, sin contar posibles interrupciones de la prescripción ${ }^{47}$. Esta situación existente en nuestro derecho no es excepcional, ya que en casi todas las legislaciones los plazos para reclamar como consecuencia de ruina o vicios graves en las edificaciones son amplios $^{48}$ incluyendo en las que puede ponerse como ejemplo extremo los 30 años de la acción ordinaria del derecho francés ${ }^{49}$.

También cuando se ejercita la acción contractual contenida en el artículo 1.591.2. ${ }^{\circ}$ del Código Civil, la prescripción es de 15 años según el propio texto legal señala y según ha reiterado la jurisprudencia existente ${ }^{50}$.

Cuando se trate del ejercicio de las acciones del 1.907 a 1.909 del Código Civil no se puede entender que existe un término de prescripción específico, sino que será la de la acción que en el fondo se ejercite, esto es, de las acciones de defectuoso cumplimiento contractual o de garantía decenal, con lo cual en principio la prescripción sería también de 15 años desde el término de la construcción al menos — con la salvedad de que los daños se evidenciaran dentro del periodo de garantía si se trata de la ex-acción 1.591—; aunque la acción que se ejercita es la de 1.907 y siguientes y estimo que está en relación con el artículo 1.902, el término de prescripción sería de un año ${ }^{51}$.

46 Ss. 11 de octubre de 1974, Ar. 3.798; 6 de marzo de 1990, Ar. 1.672, 16 de octubre de 1991, Ar. 7.449 y 1 de octubre de 1992, Ar. 7.616.

47 Cosa distinta es en la praxis la prueba de si en tal hipótesis los vicios que existían en el momento de la reclamación judicial eran consecuencia además de una defectuosa conservación e incluso si el no reclamar en tantos años no supone en sí mismo una actuación negligente, puesto que la falta de reparación hubiera agravado los defectos originales.

48 Véase Fernández Hierro, La Responsabilidad civil por vicios...., obra citada, pp. 19 y ss.

$49 \mathrm{Si}$ bien en tales casos no opera la presunción de culpa: obra citada en nota anterior, p. 23 y ss.

50 Ss. 11 de octubre de 1974, Ar. 3.798 y 16 de diciembre de 1983, Ar. 6.960.

51 S.A. de Valencia de 14 de diciembre de 1989, R.G.D. p. 591 de 1990. 


\subsection{Médicos}

Cuando se habla de responsabilidad médica hay que distinguir la clase de actuación de que se trata: si nos encontramos en un supuesto de responsabilidad contractual, la responsabilidad civil tendrá un término de prescripción de quince años, de acuerdo con el artículo 1.964 del Código Civil $^{52}$; mientras que si la acción es extracontractual - y lo será siempre que se reclame a instituciones públicas o de la seguridad social ${ }^{53}$ - la prescripción será anual de acuerdo con el artículo 1.938.2. ${ }^{\circ}$ del Código Civil ${ }^{54}$.

\subsection{Profesiones jurídicas}

\subsubsection{Abogados y procuradores}

Si se trata de abogados y procuradores debe entenderse que cuando se trata de una reclamación como consecuencia de una actuación contractual, la prescripción sería de quince años, mientras que cuando las actuaciones fueran extracontractuales (un ejemplo puede ser la designación de abogado y procurador en turno de oficio) el plazo de reclamación sería anual por la misma conocida fundamentación que se acaba de exponer al aludir a la prescripción de las actuaciones médicas. No obstante, algún fallo dictado en materia de responsabilidad de abogado y procurador aplica la prescripción anual a las actividades de los abogados, como si hubieran sido originadas por culpa extracontractual ${ }^{55}$.

\subsubsection{Notarios y registradores}

Lo manifestado respecto a abogados y procuradores es aplicable mutatis mutandis a la actuación de los notarios.

52 La sentencia de la Audiencia de Barcelona de 4 de diciembre de 1989, R.G.D. p. 4.816 de 1990, en un supuesto de reclamación de cantidad por el médico estima que:

«... no resulta de aplicación el plazo de prescripción aplicable a la reclamación del pago por "honorarios médicos o profesionales" con los derivados de la general y compleja asistencia sanitaria, dentro de la que se incluyen conceptos o partidas tan varias y diversas -estancias, manutención, medicamentos, análisis, etc.- - que por su propia amplitud y variedad escapan y desbordan al contenido concreto de "acto médico" al que responde la contraprestación de honorarios conforme al número 2 del artículo 1.967, para entrar dentro de un esquema más amplio de "prestación de servicios" lo que determina la aplicación del plazo general de 15 años que conforme al artículo 1.964 del Código Civil corresponde a las acciones de naturaleza personal».

53 Notemos que también cuando se trata de una reclamación en vía administrativa la prescripción sería anual.

54 Ss. 18 de junio de 1987, Ar. 4.047 y 10 de octubre de 1996, Ar. 7.403 entre otras.

55 S. A.P. de Ciudad Real de 1 de septiembre de 1995, Ar. Civil 1.701. 
Mayores dudas ofrece la actuación de los registradores, ya que aun cuando perciben sus emolumentos de los clientes, no sólo ejercitan una función pública, sino que lo hacen en régimen de monopolio, con lo que aparece más borrosa la relación jurídica que les une a los interesados, ya que en tales circunstancias hablar de contrato puede ser una entelequia.

\subsubsection{Jueces y magistrados}

El artículo 904 de la Ley de Enjuiciamiento Civil señala que no se podrá interponer demanda de responsabilidad hasta que haya terminado el pleito o caso o en que se suponga causado el agravio, y de acuerdo con el artículo 905 de la propia Ley, la demanda tendrá que promoverse en los seis meses siguientes a los que se hubiera dictado la sentencia o auto que haya puesto término al pleito o causa, es decir, que hay un plazo que es de seis meses desde que se termina el procedimiento, no pudiendo tampoco promoverse antes de que se dé dicha circunstancia.

El cómputo ha de entenderse a partir de que se hubiera dictado la sentencia o auto firme ${ }^{56}$, aun cuando el propio Tribunal Supremo ha matizado que debe ser de terminación ${ }^{57}$.

Dicho plazo debe computarse como de prescripción ${ }^{58}$; notemos que la reclamación por error judicial debe iniciarse por la demanda en petición de dicha declaración deducida ante el Tribunal Supremo que debe instarse inexcusablemente en el plazo de tres meses a partir del día en que pudo practicarse de acuerdo con el artículo 293.1.a) de la Ley Orgánica del Poder Judicial.

56 S. 4 de abril de 1961, Ar. 1.799.

57 S. 21 de enero de 1968, Ar. 1.035. Notemos que del plazo que señala el artículo 905 del Código Civil no pueden deducirse los días inhábiles, de acuerdo con la sentencia de 3 de octubre de 1990, Ar. 7.468.

${ }^{58}$ La sentencia de 18 de enero de 1995, Ar. 384, señala:

«Si bien la doctrina y la jurisprudencia no se muestran unánimes a la hora de establecer si el plazo a que se refiere el artículo 905 de la Ley de Enjuiciamiento Civil es un plazo de caducidad o de prescripción, como resulta de una interpretación literal del párrafo segundo, de dicho artículo, lo cierto es que la opinión mayoritaria de la doctrina y de la jurisprudencia se pronuncian en el sentido de estimar que estamos ante un plazo de prescripción y no de caducidad. Alegada por el demandado la excepción de prescripción de la acción ejercitada, se hace necesario fijar el "dies a quo", a partir del cual ha de iniciarse el cómputo del plazo prescriptivo de seis meses que establece el artículo 905, párrafo primero, de la Ley Procesal, día inicial será aquel en que adquiere firmeza la sentencia o auto que haya puesto término al pleito o causa, a tenor de los términos en que está redactado el citado precepto». 


\section{Conclusión}

La conclusión del examen del ordenamiento jurídico respecto a la responsabilidad civil en diversas profesiones nos muestra que existen unas claras diferencias. La más favorecida — si de actividad profesional puede conceptuarse- es la de jueces y magistrados, dado que el plazo de prescripción es el más exiguo, y no sólo no se presume la culpa, sino que ésta ha de ser cualificada.

El profesional que se encuentra en peor situación es el arquitecto -y demás técnicos que intervienen en la edificación-, por el doble concepto de la presunción de culpa en su contra y de plazas de prescripción mucho más largos: y, si examinamos los supuestos que en la práctica se producen, veremos que la casuística demuestra que el grado de culpa necesario para comprometer la responsabilidad de los técnicos en la construcción habitualmente es menos elevado que el de otras profesiones.

Todo ello nos lleva a la conclusión de que si el tratamiento unitario de la responsabilidad profesional puede ser aceptable, o incluso encomiable a la hora de dibujarla doctrinalmente, siempre hay que tener en cuenta que se trata de actuaciones que tienen un tratamiento diferencial y que sólo la actuación del exégeta unifica.

Ciertamente el panorama puede caminar hacia una unificación sobre todo en función de la propuesta de directiva comunitaria en virtud de la cual se establece la presunción de culpa en contra del prestador de servicios: y, sin entrar a analizar los inconvenientes que tal concepción conlleva, habrá que esperar si el tiempo hace que la misma entre en vigor y el sentido concreto que tiene. Hasta entonces, al menos, el régimen común de la responsabilidad de los profesionales está solamente en las sombras de la caverna. 